\title{
NUMERICAL SIMULATION OF A TEMPERATURE FIELD DURING MULTI-BEADS SURFACE WELDING
}

\author{
Radoslav Kon̆ár ${ }^{1}$, Miloš Mičian ${ }^{1}$, Miloslav Málek $^{1}$, Jozef Šutka ${ }^{1}$ \\ Marek Gucwa ${ }^{2}$, Jerzy Winczek ${ }^{2}$ \\ ${ }^{1}$ Department of Technological Engineering, University of Zilina \\ Zilina, Slovakia \\ ${ }^{2}$ Department of Technology and Automation, Czestochowa University of Technology \\ Czestochowa Poland \\ radoslav.konar@fstroj.uniza.sk,milos.mician@fstroj.uniza.sk,miloslav.malek@fstroj.uniza.sk \\ jozef.sutka@fstroj.uniza.sk,mgucwa@spaw.pcz.pl,winczek@imipkm.pcz.pl
}

Received: 7 January 2021; Accepted: 11 March 2021

\begin{abstract}
The calculation results of the temperature field during multi-beads GMAW (Gas Metal Arc Welding) cladding of the S355 steel plate are presented in the paper. Numerical simulations were performed using the Sysweld ${ }^{\circledR}$ program. Two of Goldak's heat source models were chosen for calculating the temperature field for each weld bead. The original article achievement is, by selecting the right heat source model and heat loading of the finite elements, obtaining an irregular shape of the fusion zone. This irregular shape of the fusion zone is very complicated to obtain using other commercial programs for numerical welding simulation. The calculation results were verified by the dimensions (critical temperatures) of the heat affected zones (HAZ) determined in the experiment, obtaining a satisfactory agreement.
\end{abstract}

MSC 2010: 74F05, 74S05, $80 A 20$

Keywords: modeling, welding, finite element method, weld surfacing, Sysweld, S355 steel

\section{Introduction}

The multi-pass welding techniques are commonly used for joining steel structures (or other metal alloys) [1], regeneration of machine and equipment parts (rebuilding) [2], as well as for the application of welding coatings (surfacing, hardfacing) [3]. During multi-pass welding, the temperature of the object changes many times in a wide range such as heating, cooling and change in the state of the material (solid, liquid, melting, solidification). Detailed information about the temperature field during the welding process can be obtained by modeling thermal phenomena occurring in the material.

Lindgren and his colleagues introduced a fully coupled thermal, metallurgical and mechanical model for multi-pass welding analysis $[4,5]$. The simulation of 
multi-pass welding was performed using FEM (Finite Element Method). However, the first analytical models of the multi-pass butt welded joint is presented in [6].

Numerous papers have been published since then, in which numerical methods were used for analysis of thermomechanical states of multi-pass welding, a.o. in [7-15]. In many of them, theoretical (numerical) considerations were subjected to experimental verification. In [7-10] the calculated temperature field was verified by comparing theoretical and measured (using thermocouples) welding thermal cycles. In [11-15], the calculated and real shapes and sizes of fusion zones were compared.

The above publications [4-15] present the results of numerical simulations for butt and fillet welded joints. Reed and Bhadeshia [16] first proposed a simple model for rebuilding by use of the welding process. The article presents theoretical studies on the impact of interpass temperature, welding current, and temperature on the weld microstructure fraction, which is reinforced again during the production of the welded structure. In the paper [17], the parameters of Goldak's double ellipsoidal heat source model were determined for the simulation of overlapping beads on the plate, and the simulated molten pool and the HAZ (Heat Affected Zone) were compared with the macrographs of cross-sections of the experimental weldments.

Both in [16] and [17], the fusion line had a regular, approximately parabolic shape. In the case of weld surfacing, the fusion line often has an irregular shape, impossible to reproduce with commonly used heat source models. Winczek [18], based on analytical considerations, proposed a two-distributed model of a volumetric heat source. The use of this heat source model in the modeling of thermomechanical states of multi-pass weld surfacing is discussed in [19]. This paper does not present experimental verification.

In this article, an unconventional approach for correctly defining a heat source model and the simulation results of temperature fields are presented. The Sysweld program allows you to use the combination of multiple sources to define a molten region of a single bead. A combination of two of Goldak's models was used to describe the molten area of each weld bead from a six bead surface weld cladding of the S355 steel plate. The results of numerical simulations were subjected to experimental verification.

\section{Numerical simulation of welding process in Sysweld ${ }^{\circledR}$ program}

A numerical simulation of the welding process was created from the results of the experimental measurements. These parameters are necessary for defining the boundary conditions of thermal fields numerical simulation. Parameters such as weld surface geometry, molten area, and HAZ dimensions are the basic parameters for correctly defining the numerical simulation of welding. The quality of simulation results is always dependent on the quality of the input data and boundary conditions. 
A simple experiment was performed to obtain boundary conditions. Six surface beads were made on a steel S355 plate with dimensions of 300x300x30 mm. The chemical composition of S355 steel measured by spectroscopy analysis is shown in Table 1.

Table 1. Chemical composition of S355 experimental steel

\begin{tabular}{|c|c|c|c|c|c|c|c|c|}
\hline \multicolumn{10}{|c|}{ Chemical composition [wt. \%] } \\
\hline $\mathrm{C}$ & $\mathrm{Si}$ & $\mathrm{Mn}$ & $\mathrm{P}$ & $\mathrm{S}$ & $\mathrm{Al}$ & $\mathrm{Cu}$ & $\mathrm{V}$ & $\mathrm{CEV}$ \\
\hline 0.160 & 0.340 & 1.500 & 0.010 & 0.005 & 0.034 & 0.010 & 0.004 & 0.410 \\
\hline
\end{tabular}

The weld was created by GMAW technology, the filler material was wire Lincoln Ultra MAG (G42 3 C 3Sil according to EN ISO 14 341-A) with a $1.20 \mathrm{~mm}$ diameter. A constant welding speed $\mathrm{v}_{\mathrm{s}}$ and the time between bead welding was ensured during the experiment by a robotic welding torch manipulator. Shielding gas was Argon MIX M21 according to EN ISO 14175 with a flow of $121 \cdot \mathrm{min}^{-1}$ (the shielding gas was composed of $82 \% \mathrm{Ar}+18 \% \mathrm{CO}_{2}$ ). Welding parameters are shown in Table 2 . The welding parameters $\mathrm{I}, \mathrm{U}$, and $\mathrm{v}_{\mathrm{w}}$ were determined directly from the welding machine after welding each bead. These parameters represent average values during welding of all beads. The welding heat input Q was calculated for a GMAW welding efficiency of $\mu=0.8$.

Table 2. Welding parameters

\begin{tabular}{|c|c|c|c|c|c|c|}
\hline $\begin{array}{c}\text { Welding } \\
\text { bead }\end{array}$ & $\begin{array}{c}\text { Welding } \\
\text { current } \\
\mathrm{I}[\mathrm{A}]\end{array}$ & $\begin{array}{c}\text { Arc voltage } \\
\mathrm{U}[\mathrm{V}]\end{array}$ & $\begin{array}{c}\text { Welding } \\
\text { speed } \\
\mathrm{v}_{\mathrm{s}}\left[\mathrm{mm} \cdot \mathrm{s}^{-1}\right]\end{array}$ & $\begin{array}{c}\text { Wire feed } \\
\text { speed } \\
\mathrm{v}_{\mathrm{w}}\left[\mathrm{m} \cdot \mathrm{min}^{-1}\right]\end{array}$ & $\begin{array}{c}\text { Heat input } \\
\mathrm{Q}\left[\mathrm{J} \cdot \mathrm{mm}^{-1}\right]\end{array}$ & $\begin{array}{c}\text { Welding } \\
\text { position }\end{array}$ \\
\hline $1^{\text {st }}-6^{\text {th }}$ & 290.00 & 28.30 & 6.67 & 9.50 & 985.84 & PA \\
\hline
\end{tabular}

The sample was placed loosely on the work table during welding and cooling. The ambient temperature during welding was $20^{\circ} \mathrm{C}$. The length of each surface bead was $200.00 \mathrm{~mm}$, and the pause between the welding of the individual bead was $3.00 \mathrm{~s}$. The individual welds were welded successively side by side in one direction. The welding sequence scheme is in Figure 1.

The most important information for defining the geometry of the FEM model and the parameters of the heat source is the macrostructure of the weld. The macrostructure and its simplified digital geometry are shown in Figure 2.

The thermal load of the system from the heat supplied by the mathematical heat source is the main element in the welding simulation. In our case, Goldak's model was used to simulate temperature fields during welding. Goldak's model is one of the most popular mathematic heat source models, and it's typical for arc welding methods with a moving heat source. The scheme of Goldak's model is shown in Figure 3. 


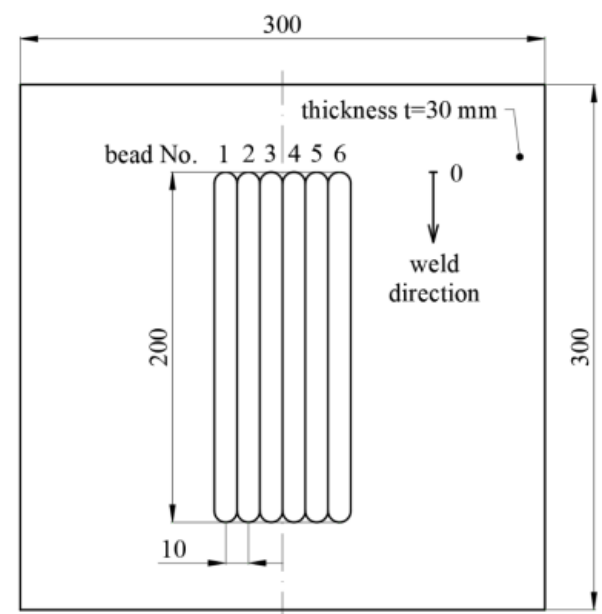

Fig. 1. Welding sequence scheme

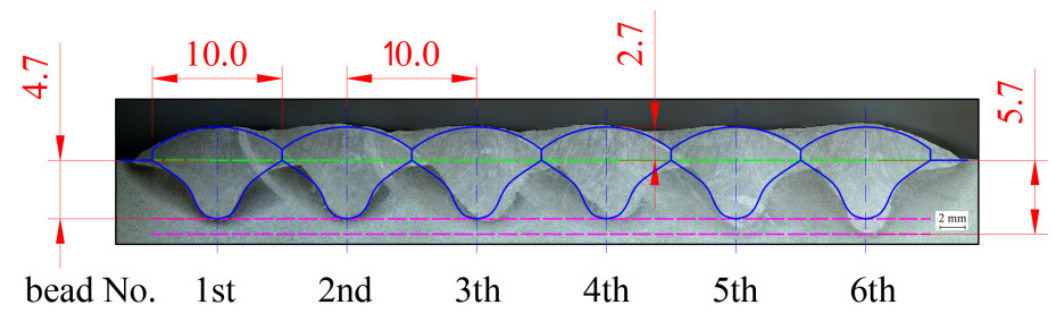

Fig. 2. Weld macrostructure and its geometry

Goldak's heat source model is defined as heat flux density into the material. The mathematical source description is given in formulas (1) and (2) [20].

The efficiency of the heat transfer into the base material is given by the applied welding method. The geometry of the double-ellipsoidal model can be modified by changing coefficients 'a', 'b', and 'c' in Eqs. (1) and (2) (Fig. 3). Transferred heat is described by the equations below:

- for the front part of the double-ellipsoidal model, the equation is:

$$
Q_{f}(x, y, z)=\frac{6 \cdot \sqrt{3} \cdot f_{f} \cdot Q}{a \cdot b \cdot c_{1} \cdot \pi \cdot \sqrt{\pi}} \exp \left(\frac{-3 x^{2}}{a^{2}}\right) \exp \left(\frac{-3 y^{2}}{b^{2}}\right) \exp \left(\frac{-3 z^{2}}{c^{2}}\right)
$$

- for the rear part of the double-ellipsoidal model, the equation is:

$$
Q_{f}(x, y, z)=\frac{6 \cdot \sqrt{3} \cdot f_{f} \cdot Q}{a \cdot b \cdot c_{1} \cdot \pi \cdot \sqrt{\pi}} \exp \left(\frac{-3 x^{2}}{a^{2}}\right) \exp \left(\frac{-3 y^{2}}{b^{2}}\right) \exp \left(\frac{-3 z^{2}}{c^{2}}\right)
$$

where:

$Q_{f}, Q_{r}[-]-$ heat introduced into the front and the rear part of the model, $Q \quad[\mathrm{~W}]-$ total power source, 
a $\quad[\mathrm{mm}]$ - width of the molten pool,

$b \quad[\mathrm{~mm}]$ - penetration of the molten pool,

$c_{1}, c_{2}[\mathrm{~mm}]$ - length of the front and the rear part of the molten pool,

$f_{f}, f_{r}[-]-$ constants which influence energy flow intensity into the material $\left(f_{f}=1.000, f_{r}=0.833\right.$ in Sysweld $)$.

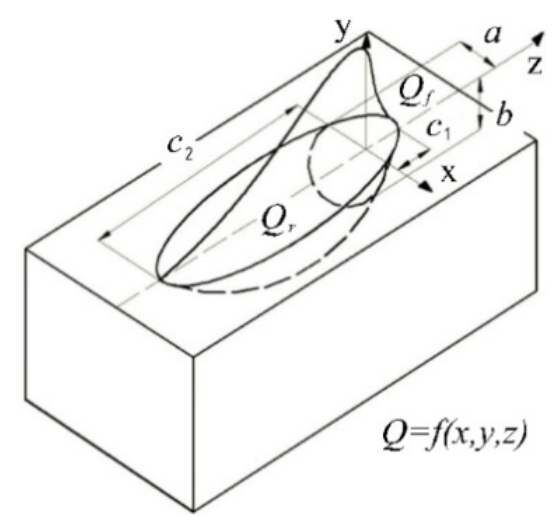

Fig. 3. Weld macrostructure and its geometry [22]

The shape of the molten area in the welding simulation can be achieved by correctly setting the Goldak model parameters. It is also possible to use several Goldak sources, mainly to define the irregular shape of the molten area.

In the present article, the macrostructure has an irregular shape, which cannot be described by a single heat source. The shape of the molten zone on the macrostructure has an irregular shape, which is typical for arc welding in a shielding gas composed of $\mathrm{Ar}+\mathrm{CO}_{2}$. Two of Goldak's sources need to be used to describe this specific one bead molten area. Goldak's sources parameters are listed in Table 3.

Table 3. Parameters of combined Goldak's model heat source

\begin{tabular}{|l|c|c|}
\hline \multicolumn{1}{|c|}{ Parameters of heat source } & Heat source No.1 & Heat source No.2 \\
\hline Welding velocity $\mathrm{v}_{\mathrm{w}}\left[\mathrm{cm} \cdot \mathrm{min}^{-1}\right]$ & 40.00 & 40.00 \\
\hline Lenght of heat source $\mathrm{c}_{1}+\mathrm{c}_{2}[\mathrm{~mm}]$ & $(2.70+5.30)=8.00$ & $(2.70+5.30)=8.00$ \\
\hline Width of heat source $2 \cdot \mathrm{a}[\mathrm{mm}]$ & 10.00 & 0.50 \\
\hline Penetration of heat source $\mathrm{b}[\mathrm{mm}]$ & 2.00 & 2.00 \\
\hline The displacement heat source in $\mathrm{X}$-axis $\Delta \mathrm{X}[\mathrm{mm}]$ & 0.00 & 0.00 \\
\hline The displacement heat source in $\mathrm{Y}$-axis $\Delta \mathrm{X}[\mathrm{mm}]$ & 0.00 & -11.00 \\
\hline The displacement heat source in Z-axis $\Delta \mathrm{X}[\mathrm{mm}]$ & 6.00 & -2.00 \\
\hline Input energy in simulation $\mathrm{Q}\left[\mathrm{J} \cdot \mathrm{mm}^{-1}\right]$ & 650.00 & 200.00 \\
\hline
\end{tabular}

The Sysweld ${ }^{\circledR}$ simulation program is divided into two calculation modules. The first is thermo-metallurgical and the second is mechanical. The calculation of 
temperature fields and cycles can be realized only in the thermo-metallurgical module.

The 2D cross-section model was used for the thermo-metallurgical simulation process in the program Sysweld ${ }^{\circledR}$. The 2D cross-section model has the same geometrical dimensions as the experimental sample cross-section. The surface shape of the weld was modified to simplify the deficiency of Goldak's heat sources. The same cross-section geometry was used for all weld beads for simplicity. The width of the experimental model for simulation was $300.00 \mathrm{~mm}$, and the thickness was $30.00 \mathrm{~mm}$.

The distribution model has 1202 2D finite elements, 878 1D finite elements, and 1983 nodes. The smallest element used in the FEM model is in the area of the weld with a dimension of $1.00 \mathrm{~mm} \times 1.00 \mathrm{~mm} \times 1.00 \mathrm{~mm}$. Six trajectories and one reference for the movement of the heat source were created. The length of the trajectory and reference was $200.00 \mathrm{~mm}$ as in the real experiment. The trajectory position defines the heat source's center position, and the reference position defines the heat source orientation in numerical simulation (Fig. 4).

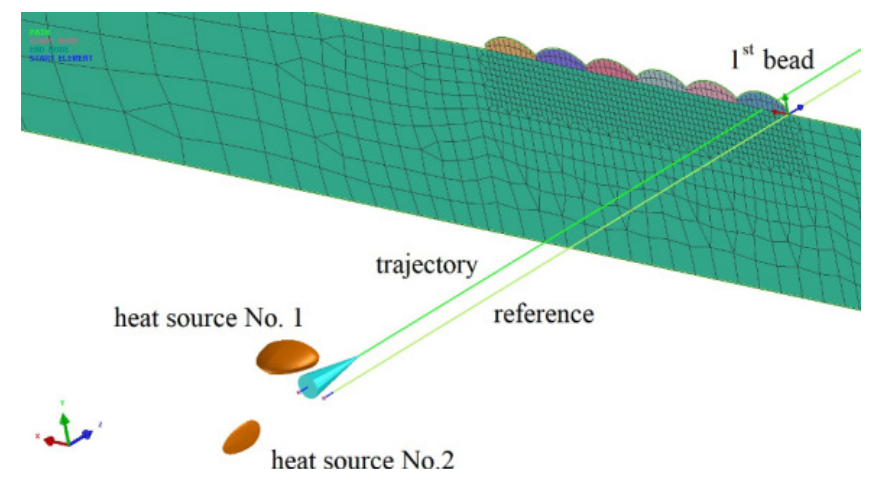

Fig. 4. 2D cross-section FEM model with visualized Goldak models

The shape of the molten zone can also be influenced by the selection of finite elements through which energy will be distributed to the model. These finite elements are called 2D-LOAD. The finite elements of 2D-LOAD must be selected for each bead to achieve the correct shape. 2D-LOAD finite elements are shown in Figure 5.

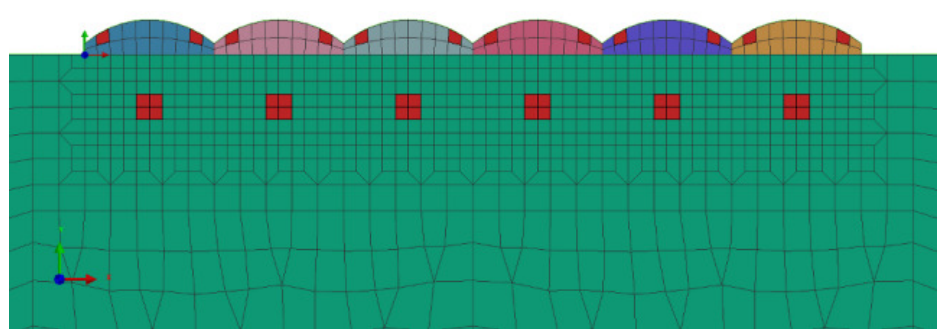

Fig. 5. Model 2D-LOAD finite elements 
The convection heat transfer coefficient is an important parameter for thermal analysis during welding but especially cooling. The convection and radiative losses were set to $25.00 \mathrm{~W} \cdot \mathrm{m}^{-2} \cdot \mathrm{K}^{-1}$. The numerical simulation of the temperature analysis was completed at $7200.00 \mathrm{~s}$ from the start of welding.

\section{Simulation results of thermal analysis in Sysweld ${ }^{\circledR}$ program}

For each welded bead, an individual 2D model was calculated. The heat source model was calibrated to achieve the best fit with the real geometry of molten zones on macrostructure views. The achieved agreement between the real and simulated molten zone for $1^{\text {st }}$ weld bead is shown in Figure 6.

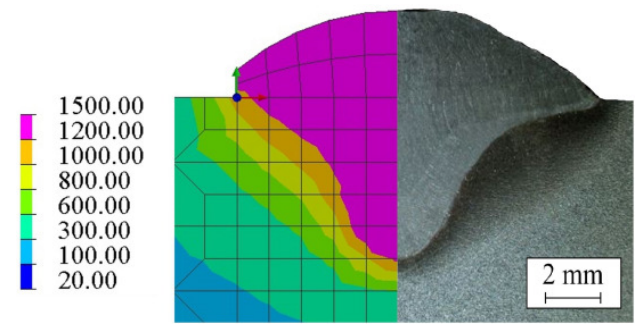

Fig. 6. Comparison of the real and simulated molten zone for the $1^{\text {st }}$ weld bead

The results of numerical calculations in the Sysweld ${ }^{\circledR}$ program provide information on the temperature distribution and propagation in the model during welding and cooling. The molten zone geometry, temperature fields, and HAZ during the welding of the first and sixth layers are shown in Figure 7.

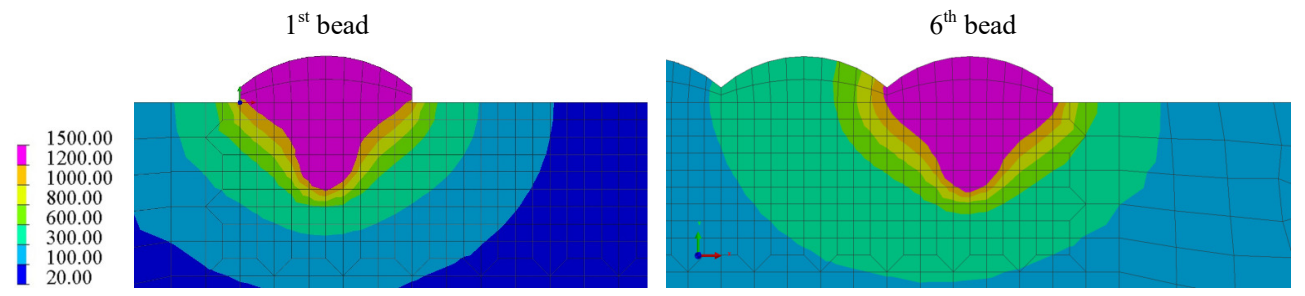

Fig. 7. Molten zone and temperature fields during welding of the first and the sixth weld bead

It is very important to know the change in temperature over time when analyzing the welding process. Numerical analysis of temperature fields provides a wealth of information on heat dissipation and temperature changes. Real temperature cycles were not measured in the experiment. The definition of the heat source, in this case, was based on the molten zone and the HAZ zone. Calculated temperature cycles can be analyzed at any node of the FEM model. The temperature fields for the selected points located in the molten zones are shown in Figure 8. 


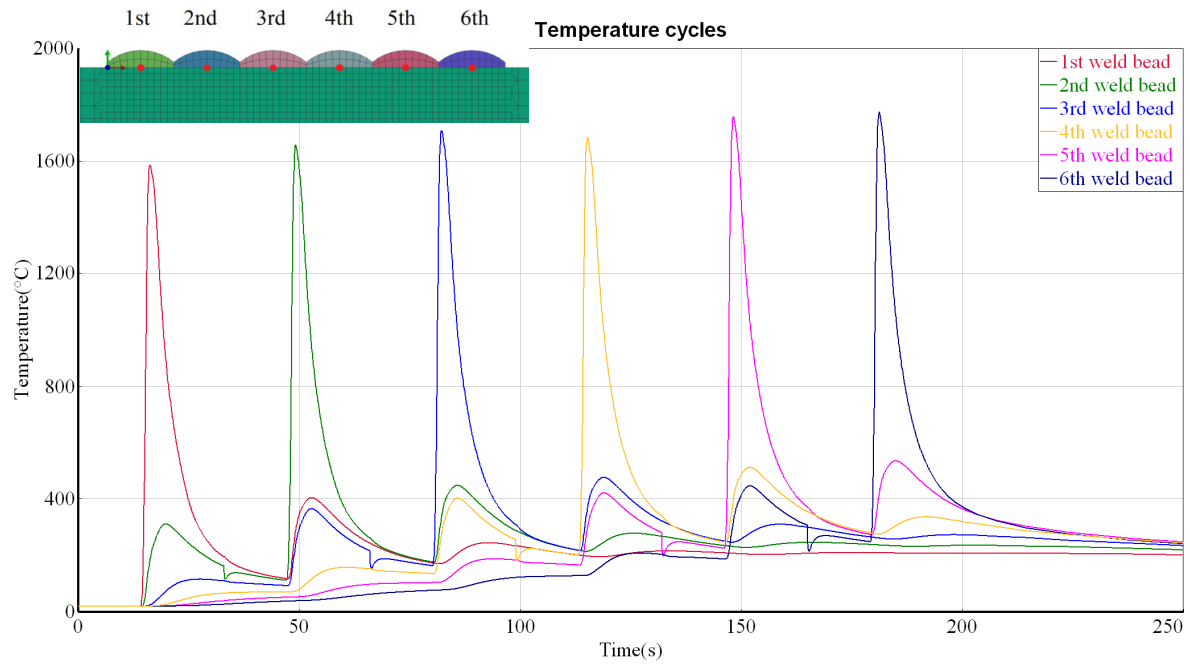

Fig. 8. Simulated temperature fields at selected points in molten zones and the point location

The drop in temperature during the temperature cycles is caused by the restart of the numerical task at the beginning of the bead welding at times of $33.00 \mathrm{~s}$, $66.00 \mathrm{~s}, 99.00 \mathrm{~s}, 132.00 \mathrm{~s}$ and $165.00 \mathrm{~s}$. The temperature drop occurs only in the temperature cycle, which is measured at the location of the next layer. This is caused by turning on the $2 \mathrm{D}$ elements of the currently welded layer. The temperature fields for the selected points located in the HAZ are shown in Figure 9.

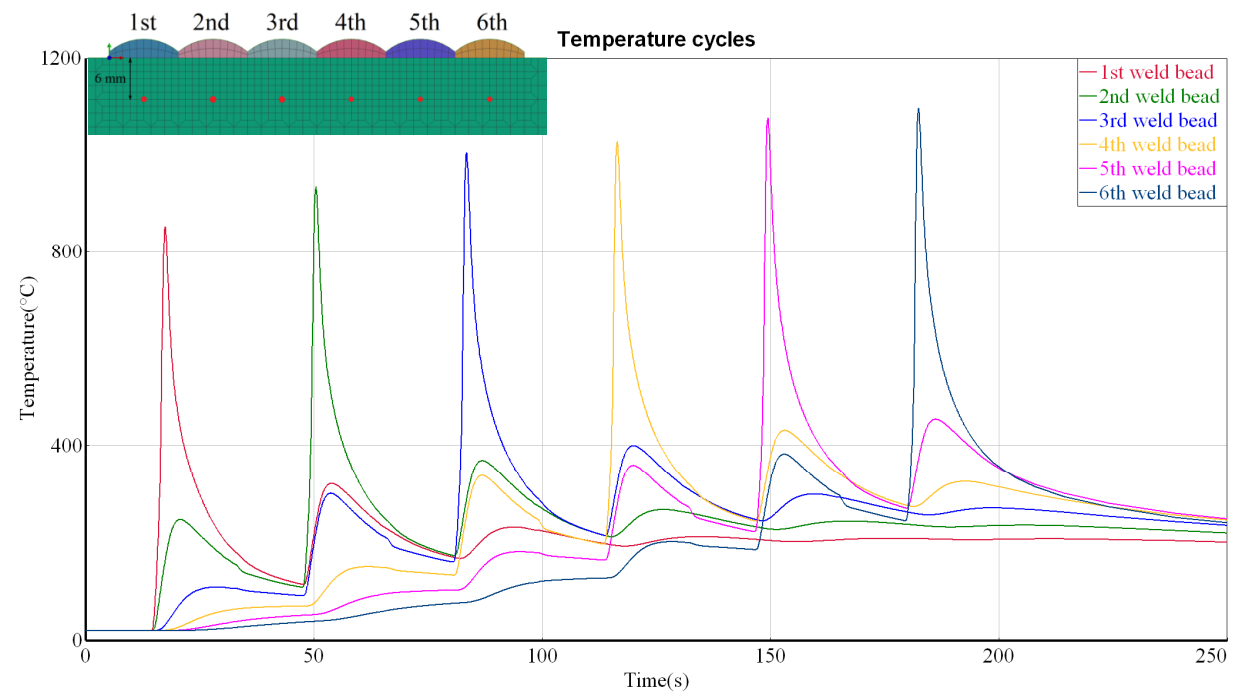

Fig. 9. Simulated temperature fields at selected points in HAZ and the point location 
The thermal saturation of the material can be seen in both graphs (Figs. 8 and 9) of temperature cycles. The result is a steady increase in the value of $T_{\max }$ and time $t_{8 / 5}$. The values of these parameters are listed in the Table 4 .

Table. 4. Characteristic parameters of thermal cycles in HAZ

\begin{tabular}{|l|c|c|c|c|c|c|}
\hline \multirow{2}{*}{ Parameters } & \multicolumn{7}{|c|}{ Bead No. } \\
\cline { 2 - 7 } & $1^{\text {st }}$ & $2^{\text {nd }}$ & $3^{\text {rd }}$ & $4^{\text {th }}$ & $5^{\text {th }}$ & $6^{\text {th }}$ \\
\hline $\mathrm{T}_{\max }\left[{ }^{\circ} \mathrm{C}\right]$ & 853.1 & 936.0 & 1005.5 & 1030.3 & 1076.6 & 1098.9 \\
\hline $\mathrm{t}_{8 / 5}[\mathrm{~s}]$ & 1.9 & 2.6 & 3.5 & 4.1 & 5.0 & 5.6 \\
\hline
\end{tabular}

$\mathrm{T}_{\max }$ - maximal temperature of thermal cycles

$\mathrm{t}_{8 / 5}$ - the cooling time from 800 to $500^{\circ} \mathrm{C}$

It is possible to predict austenite decay structures from calculated values for any point in the HAZ zones or weld metal. A CCT diagram or a suitable calculation program can be used to predict the decay structures, their contents, and hardness of the surface weld joint. Subsequently, it is possible to calculate the residual stresses and deformations.

\section{Conclusions}

Numerical calculations in welding are a powerful tool nowadays for predicting the performance of welded joints. The calculation of temperature fields and temperature cycles is the first step to credible numerical results. Not only is the correct material database important, but also the correct definition of the Goldak temperature model of the heat source for the correct calculation of the temperature analysis. The correct thermal loading of the system, and thus the accuracy of the numerical temperature analysis, depends on the correct geometry of the molten area.

The present article describes the correct procedure for defining the source model for the irregular shape of the molten area for a 6-layer weld in the SYSWELD program. The use of two sources is used to correctly define the molten area. The centers of the used sources are shifted relative to each other in the direction of movement of the source. A tool for defining 2D elements through which heat is distributed to the model is also used. The correctness of defining the molten area is compared with the macrostructure of the weld. The results of the temperature analysis, the temperature fields, and temperature cycles show for selected points. The results of the multi-beads welding simulation also make it possible to observe the effect of the supplied heat from welding on the $t_{8 / 5}$ time extension.

The results of the temperature analysis are one of the most important parameters for the implementation of the following calculations, such as the calculation of structural changes, hardness, residual stresses, and deformations. 


\section{References}

[1] Sladek, A., Patek, M., \& Mičian, M. (2017). Behavior of steel branch connections during fatigue loading. Archives of Metallurgy and Materials, 62(3), 1597-1601. DOI: 10.1515/amm-2017-0244.

[2] Mičian, M., \& Konar, R. (2017). Repairs of damaged castings made of graphitic cast iron by means of brazing. Archives of Foundry Engineering, 17(3), 91-96. DOI: 10.1515/afe-2017-0097.

[3] Winczek, J., Gucwa, M., Mician, M., Konar, R., \& Parzych, S. (2019). The evaluation of the wear mechanism of high-carbon hardfacing layers. Archives of Metallurgy and Materials, 64(3), 1111-1115.

[4] Lindgren, L.E., Runnemalm, H., \& Näsström, M.O. (1999). Simulation of multipass welding of a thick plate. International Journal for Numerical Methods in Engineering, 44, 1301-1316.

[5] Börjesson, L., \& Lindgren, L.E. (2001). Simulation of multipass welding with simultaneous computation of material properties. Journal of Engineering Materials and Technology, 123(1), 106-111. DOI: $10.1115 / 1.1310307$.

[6] Fassani R.N.S., \& Trevisan O.V. (2003). Analytical modeling of multipass welding process with distributed heat source. Journal of the Brazilian Society of Mechanical Sciences and Engineering, 25(3), 303-305.

[7] Deng, D., Murakawa, H., \& Liang, W. (2008). Numerical and experimental investigations on welding residual stress in multi-pass butt-welded austenitic stainless steel pipe. Computational Materials Science, 42, 234-244.

[8] Heinze, C., Schwenk, C., \& Rethmeier, M. (2012). Numerical calculation of residual stress development of multi-pass gas metal arc welding. Journal of Constructional Steel Research, 72, 12-19. DOI: 10.1016/j.jcsr.2011.08.011.

[9] Gao, H., Dutta, R.K., Huizenga, R.M., Amirthalingam, M., Hermans, M.J.M., \& Richardson, I.M. (2014). Pass-by-pass stress evolution in multipass welds. Science and Technology of Welding and Joining, 19(3), 256-264. DOI: 10.1179/1362171813Y.0000000191.

[10] Ganesh, K.C., Balasubramanian, K.R., Vasudevan, M., Vasantharaja, P., \& Chandrasekhar, N. (2016). Effect of multipass TIG and activated TIG welding process on the thermo-mechanical behavior of 316LN stainless steel weld joints. Metallurgical and Materials Transactions B, 47B, 1347-1362. DOI: 10.1007/s11663-016-0600-6.

[11] Giętka, T., Ciechacki, K., \& Kik, T. (2016). Numerical simulation of duplex steel multipass welding. Archives of Metallurgy and Materials, 61(4), 1975-1984. DOI: 10.1515/amm-2016-0319.

[12] Novotný, L., de Abreu, H.F.G., de Miranda, H.C., \& Béreš, M. (2016). Simulations in multipass welds using low transformation temperature filler material. Science and Technology of Welding and Joining, 21(8), 680-687. DOI: 10.1080/13621718.2016.1177989.

[13] Konar, R., \& Patek, M. (2017). Numerical simulation of dissimilar weld joint in Sysweld simulation software. Tehnicki Vjesnik - Technical Gazette, 24(1), 137-142. DOI: 10.17559/TV20150513074103.

[14] Sajek, A., (2019). Application of FEM simulation method in area of the dynamic of cooling AHSS steel with a complex hybrid welding process. Welding in the World, 63, 1065-1073. DOI: 10.1007/s40194-019-00718-z.

[15] Kik, T., Moravec, J., \& Novakova, I. (2019). Numerical simulations of X22CrMoV12-1 steel multilayer welding. Archives of Metallurgy and Materials, 64(4), 1441-1448.

[16] Reed, R.C., \& Bhadeshia, H.K.D. (1994). A simple model for multipass steel welds. Acta Metallurgica Materialia, 42, 3663-3678.

[17] Joshi, S., Hildebrand, J., Aloraier, A.S., \& Rabczuk, T. (2013). Characterization of material properties and heat source parameters in welding simulation of two overlapping beads on a substrate plate. Computational Materials Science, 69, 559-565.

[18] Winczek, J. (2011). New approach to modeling of temperature field in surfaced steel elements. International Journal of Heat and Mass Transfer, 54, 4702-4709. 
[19] Winczek, J. (2017). Modeling of temperature field during multi-pass GMAW surfacing or rebuilding of steel elements taking into account the heat of the deposit metal. Applied Sciences, 7(1), 6, 1-19. DOI: 10.3390/app7010006.

[20] Kik, T., Moravec, J., \& Novakova, I. (2018). Application of numerical simulations on 10GN2MFA steel multilayer welding. Dynamical system in applications - 14th International Conference on Dynamical Systems, Lodz, Poland. 249, 193-204. DOI: 10.1007/978-3-31996601-4_18.

[21] Mičian, M., et al. (2020). Investigation of welds and Heat Affected Zones in weld surfacing steel plates taking into account the bead sequence. Materials, 13, 5666. DOI: 10.3390/ma13 245666.

[22] Konar, R., Mician, M., \& Zrak, A. (2018). Lap weld joint modelling and simulation of welding in programme SYSWELD. XXII Slovak-Polish Scientific Conference on Machine Modelling and Simulations 2017 (MMS 2017), 157, 02018,_DOI: 10.1051/matecconf/201815702018. 